\begin{tabular}{c} 
journal homepage: http://ijiemjournal. uns.ac.rs/ \\
International Journal of Industrial \\
Engineering and Management \\
Volume $12 /$ No $4 /$ December $2021 / 262-273$ \\
\hline
\end{tabular}

Original research article

\title{
Additive and subtractive rapid prototyping techniques: a comparative analysis of FDM \& CNC processes
}

\author{
A. Neuenfeldt-Junior ${ }^{\mathrm{a}}$, M. Cheiram ${ }^{\mathrm{a}}$, M. Eckhardt ${ }^{\mathrm{a}}$, C. Scheuer ${ }^{\mathrm{a}}$, J. Siluk ${ }^{\mathrm{a}}$, and M. Francescatto ${ }^{\mathrm{a}}$ \\ ${ }^{a}$ Federal University of Santa Maria, Santa Maria, Brazil
}

A B STRACT

The present research addresses a comparative analysis among Additive (ARP) and Subtractive (SRP) rapid prototyping techniques, aiming to determine which approach presents greater technical and economic viability for physical prototype manufacturing. The Analytic Hierarchy Process (AHP) multi-criteria decision method was used to categorize and quantify the analysis criteria. The analyzed Rapid Prototyping (RP) techniques were the Computer Numerical Control (CNC) milling as SRP technique and the Fused Deposition Modeling (FDM) process as ARP. The SRP rapid prototyping technique is the most suitable alternative for manufacturing prototypes, according to the analyzed evaluation criteria.
ARTICLE INFO

Article history:

Received April 20, 2021

Revised August 9, 2021

Accepted August 14, 2021

Published online November 9, 2021

Keywords:

subtractive rapid prototyping; additive rapid prototyping; rapid prototyping process selection; analytic hierarchy process; multi-criteria decision analysis.

${ }^{*}$ Corresponding author: Alvaro Neuenfeldt-Junior alvjr2002@hotmail.com

\section{Introduction}

Rapid prototyping is the generic term used to designate a set of technologies integrated by Computer-Aided Design (CAD) and Computer-Aided Manufacturing (CAM) systems, used to manufacture conceptual virtual or physical prototypes [1]. The manufacturing of conceptual physical prototypes is realized through additive or subtractive processes or even using virtual techniques. Rapid Prototyping (RP) techniques can be grouped under three distinct classifications: Additive (ARP); subtractive (SRP); and virtual. On the ARP and SRP approaches, the materials are cut or stacked layer-by-layer, where a three-dimensional CAD digital model can be transformed into a physical part or set. In contrast, virtual processes employ advanced computer-based visualization technologies [2].

For new product development, generate a prototype before investing large resources amounts is necessary for the assembly of new production lines. Thus, the prototype is needed to solve design problems and to assess the project's technical feasibility before the product is ready to be manufactured and commercialized [3]. One of the main objectives of design methods for prototyping is to acquire enough information to advance product development with minimal time and cost. RP aims to improve commu- 
nication between those involved in the development process, enabling the detection of errors and failures in the early design stages, adding quality, reliability, and lower cost $[4,5]$.

The manufacturing of physical conceptual prototypes can be accomplished through additive or subtractive manufacturing techniques. Both technologies allow the prototypes' manufacture from different materials and with varied shapes [6-8]. However, the choice of the most suitable additive and subtractive $\mathrm{RP}$ techniques to manufacture prototypes is a difficult task even for experienced RP technology users [9]. Over the years, studies focused on developing RP systems selection procedures were developed using different approaches. These methods can be grouped into three distinct categories, given the de-

Table 1. Main research addressing the AHP method application for RP techniques selection. MCDM acronyms: Analytic Hierarchy Process (AHP); Preference Ranking Organization Method for Enrichment Evaluation (PROMETHEE); Multi-Attribute Utility Theory (MAUT); and Technique for Order of Preference by Similarity to Ideal Solution (TOPSIS). RP technique acronyms: Stereolithography Apparatus (SLA); Laminated Object Manufacturing (LOM); Fused Deposition Modeling (FDM); Selective Laser (SLS); Jet-wax (IJM); Jet-photopolymer (PJ); Three Dimensional Printing (3DP); Solid Ground Curing (SGC); Direct Metal Laser Sintering (DMLS); Technical Data Package (TDP); ColorJet Printing (CJP); MultiJet Printing (MJP); Masked Stereolithography (MSLA); Masked Selective Laser (MSLS); Masked Three Dimensional Printing (M3DP); Digital Light Processing (DLP); and Inkjet Printing (IJP)

\begin{tabular}{|c|c|c|c|}
\hline Ref. & Criteria & MCDM method & RP technique \\
\hline$[20]$ & $\begin{array}{l}\text { Equipment costs, geometric features, manufacture time and } \\
\text { cost, and raw materials availability. }\end{array}$ & AHP & SLA, LOM, FDM, MJM, SLS \\
\hline$[21]$ & $\begin{array}{l}\text { Office compliance, machine preparation time, prototype } \\
\text { construction and post-processing, raw materials availability; } \\
\text { costs, geometric features, and maximum prototype size. }\end{array}$ & AHP & $\begin{array}{l}\text { SLA, LOM, FDM, MJM, SLS, } \\
\text { IJM, PJ, 3DP }\end{array}$ \\
\hline$[22]$ & Geometric features and prototype manufacture time and cost. & AHP, MAHP & Unidentified ARP processes \\
\hline [23] & $\begin{array}{l}\text { Equipment costs, geometric features, manufacture time and } \\
\text { cost, raw material cost, raw materials availability, and maximum } \\
\text { prototype size. }\end{array}$ & AHP & $\begin{array}{l}\text { SLA, LOM, FDM, SLS, SGC, } \\
\text { 3DP. }\end{array}$ \\
\hline [24] & $\begin{array}{l}\text { Geometric features, raw materials availability, post-processing } \\
\text { (cure and finish), mechanical properties (resistance to impact } \\
\text { and flexural strength). }\end{array}$ & AHP & $\begin{array}{l}\text { SLA, SLS, FDM, TDP, DMLS, } \\
\text { CJP, MJP }\end{array}$ \\
\hline$[25]$ & $\begin{array}{l}\text { Material compatibility, geometrical complexity, and minimum } \\
\text { feature size. }\end{array}$ & AHP-TOPSIS & LIFT, MSLA, MSLS, M3DP \\
\hline$[26]$ & $\begin{array}{l}\text { Geometric features, manufacture time and cost, and mechanical } \\
\text { properties (elongation and strength). }\end{array}$ & AHP & MJM, SAS, DLP, FDM \\
\hline$[27]$ & $\begin{array}{l}\text { Geometric features, raw materials type and cost, and } \\
\text { mechanical properties (tensile strength). }\end{array}$ & AHP-TOPSIS & FDM \\
\hline$[28]$ & Geometric features and manufacture time and cost. & AHP & FDM \\
\hline [29] & $\begin{array}{l}\text { Geometric features, mechanical properties (tensile strength), } \\
\text { and manufacture time and cost. }\end{array}$ & $\begin{array}{l}\text { AHP, Fuzzy AHP, and } \\
\text { PROMETHEE }\end{array}$ & SLS, FDM, 3DP, IJP \\
\hline$[30]$ & Geometric features and manufacture time and cost. & AHP, MAUT & SLS, FDM \\
\hline$[31]$ & $\begin{array}{l}\text { Geometric features, mechanical properties (hardness, } \\
\text { stiffness, strength), manufacture volume, wall thickness, shape } \\
\text { complexity, machinability, and maximum prototype size. }\end{array}$ & Fuzzy AHP & $\begin{array}{l}\text { CNC milling, robot milling, and } \\
\text { DMLS }\end{array}$ \\
\hline$[32]$ & $\begin{array}{l}\text { Geometric features, mechanical properties (tensile strength) } \\
\text { and manufacture time and cost. }\end{array}$ & AHP & SLS, FDM, 3DP \\
\hline [33] & $\begin{array}{l}\text { Geometric features, manufacture time and cost, and pollution } \\
\text { control. }\end{array}$ & AHP & SLS, FDM, 3DP \\
\hline [34] & $\begin{array}{l}\text { Geometric features, mechanical properties (tensile strength), } \\
\text { and manufacture time and cost. }\end{array}$ & AHP, Fuzzy TOPSIS & SLA, LOM, FDM, SLS \\
\hline
\end{tabular}


cision support technique used [10]: Database-based approaches [11-13]; knowledge engineering-based approaches [14-19]; and multi-criteria decision-making-based approaches.

For the Multi-criteria Decision-Making (MCDM) based approach, an expressive number of researchers have successively applied the Analytic Hierarchy Process (AHP) method for the RP process selection. Table 1 summarizes the investigated RP techniques and the evaluated analysis criteria. The main analysis criteria are related to prototype geometric features, manufacturing time, and manufacturing cost, almost exclusively focused on ARP technique selection, leaving SRP unassisted, which remains an available knowledge gap in the scientific literature explored in the present research.

Thereby, the main objective of this study AHP method was used to accomplish the analysis and decision-making for selection among FDM ARP and CNC-milling SRP techniques, aiming to determine which approach presents greater technical and economic viability for a specific physical prototype manufacturing. Manufactured prototype geometric features (accuracy and roughness), cost, and time were determined to mutual comparison performing among the techniques. The application potential of the quoted method lies in developing a view of the selection problem, which is usually left in the background by available design tools. The approach in this research aims to assist professionals in the tactical manufacturing management area in verifying the potentials and limitations of FDM ARP and CNCmilling SRP techniques, enabling to facilitate the identification of which technique should be applied according to the characteristics of a specific physical prototype manufacturing.

\section{Material and methods}

The flowchart presented in Figure 1 details the research phases.

Prototypes can be manufactured using different techniques. The RP techniques employed in this study were the CNC Milling as SRP technique and FDM as ARP, and Acrylonitrile Butadiene Styrene (ABS) as a raw material. For the FDM technique, two prototypes were printed using the solid and materialsaving functions (here called alternatives $\mathrm{A} 1$ and $\mathrm{A} 2$, respectively. A3 corresponds to the $\mathrm{CNC}$ Milling prototype).

To print A1 and A2, a Stratasys 3D FDM printer model U Print SE Plus was used. This equipment

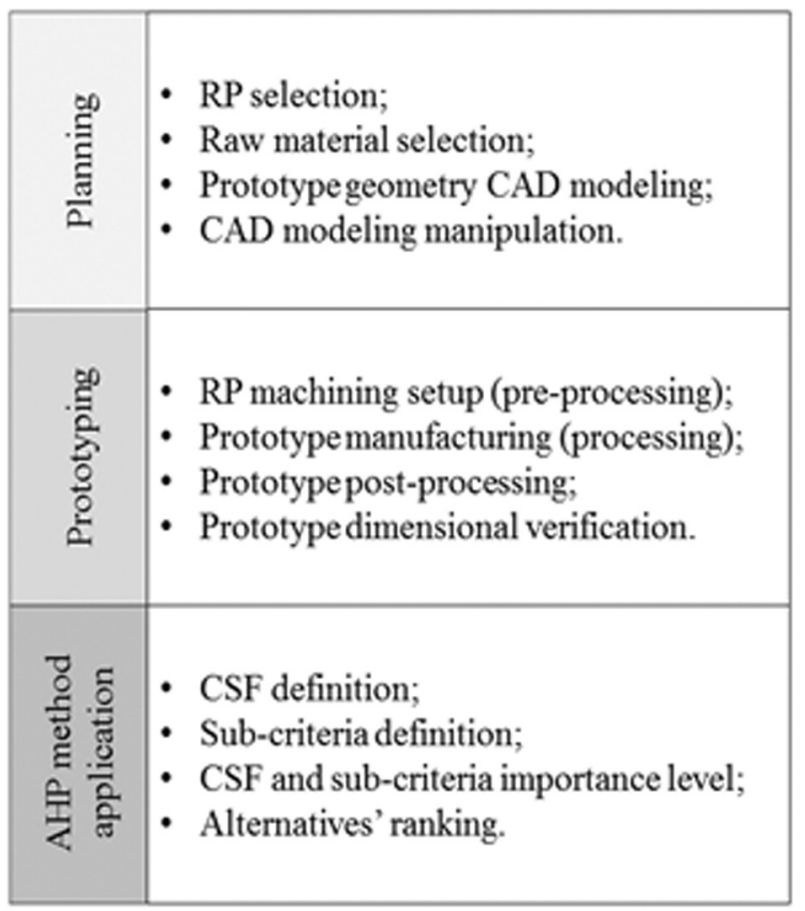

Figure 1. Research phases

features a 203 x 203 x $152 \mathrm{~mm}^{3}$ envelope. The material deposition rate was $5 \mathrm{~mm}^{3} / \mathrm{h}$, and the deposited layer thickness of $0.33 \mathrm{~mm}$. As raw material for the deposited and filling material, Stratasys ABS-M30 and Stratasys SR-30 consumables were used, respectively. To remove the filling material from the prototype, a WaveWash cleaning system was employed. This system dissolves the support material using a water-based solution without the use of hands and supervision. After the prototype is immersed in the solution and the equipment controls agitation and temperature to remove the remaining support material [35-37]. For A1 prototype printing, volumes of 72.91 and $3.66 \mathrm{~cm}^{3}$ of deposition and filling material were used, and $35.24 \mathrm{~cm}^{3}$ and $3.66 \mathrm{~cm}^{3}$ for $\mathrm{A} 2$, with a raw material waste of $5 \%$ and $9 \%$ for $\mathrm{A} 1$ and $\mathrm{A} 2$, respectively.

To manufacture A3, a Romi D600 CNC vertical machining center was used. This equipment features a $600 \times 530 \times 580 \mathrm{~mm}^{3}$ envelope and is equipped with Fanuc Oi-mD CNC control. The machining speed used in the study was $7500 \mathrm{rpm}$, the cutting feed was $20 \mathrm{~m} / \mathrm{min}$, and the three axes feed was 30 $\mathrm{m} / \mathrm{min}$. TiN coated hard metal tools were used, constituting $20 \mathrm{~mm}$ and $8 \mathrm{~mm}$ straight flute end mills and $4 \mathrm{~mm}$ spherical end mills, and a $6 \mathrm{~mm}$ drill. The machining operation was developed without using any lubrication type. A $60 \mathrm{~mm}$ diameter and $64 \mathrm{~mm}$ length workpiece was used. The prototype's final volume is $71 \times 103 \mathrm{~mm}^{3}$, generating $60 \%$ of raw material waste.

Both evaluated rapid prototyping techniques 
to employ a 3D CAD software resource to achieve the prototype modeling. The prototype modeling was performed using SolidWorks software. A generic part was adopted as a prototype, presenting a complex geometry constituted by holes, chamfers, rounding radii, and angular surfaces (Figure 2). For the FDM technique, after modeling, the CAD file is converted to an STL extension. For the CNC Milling, the CAD file is converted to CNC code employing the Solidworks CAM software. Thus, CAD file is used by CAM as a basis for calculating tool paths, simulations (collision checks and machining times), and command coding; converting the file to be interpreted by the $\mathrm{CNC}$ machine.

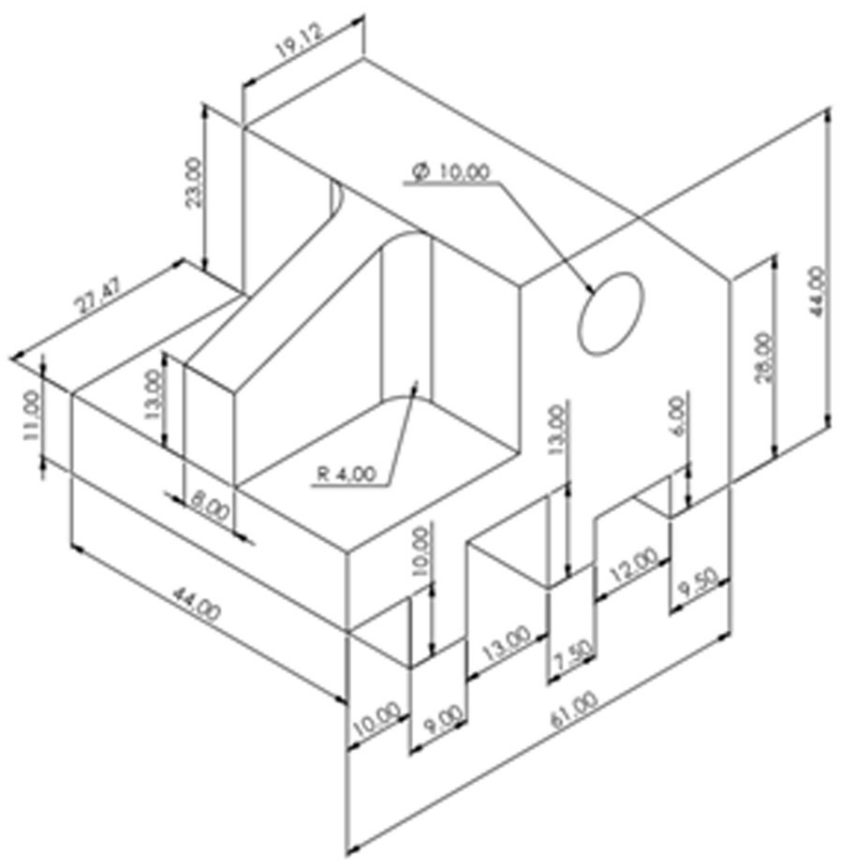

ical Success Factors (CSF). Based on the CSF, the following sub-criteria were established: Dimensional accuracy and roughness (as geometric features); preprocessing, processing, and post-processing times (as manufacturing time); and raw material cost, and general processing cost (as manufacturing cost). To quantify the CSF and sub-criteria importance level, ARP and SRP specialists must be consulted.

On the AHP method, the influencing factors decomposition is performed from top to bottom, starting with the objective, then with the CSF, sub-criteria, and alternatives (RP techniques). In this context, Figure 3 illustrates the hierarchical structure adopted in this research.

Figure 2. Prototype's dimensions (Dimensions in $\mathrm{mm}$ ).

Before starting the prototype manufacture, the machines' setup was performed. CNC and STL files are transferred to machines, tools, and raw material feed. Once the machine completes the manufacturing operation, the prototype must be removed, requiring a post-processing operation to remove prototype parts filled with filling material (holes, bumps, etc.) using a WaveWash cleaning system. The prototype dimensional verification was performed using a digital Mitutoyo absolute caliper (0.01 mm accuracy) to verify the dimensional accuracy and a Mitutoyo $\mathrm{SV}-2100 \mathrm{~W} 4$ rugosimeter $(0.05 \mu \mathrm{m}$ resolution) to access the surface finish.

The prototype geometric features, manufacturing cost, and manufacturing time are the main analysis criteria employed in the scientific literature previously indicated in Table 1, described in this study as Crit-
The alternatives $(a)$ ranking was calculated by the performance index $\left(I_{a}\right)$ considering sub-criteria $(s c)$ global importance $\left(w_{s c}\right)$ and the alternatives characteristic attributes $\left(w_{s c_{a}}\right)$ according to Eq. (1), being expressed with a score ranging from $0 \%$ to $100 \%$. To facilitate the performance analysis, $I_{a}$ is converted to a qualitative scale, separated into four levels: Noncompetitive $\left(0 \% \leq I_{a} \leq 25 \%\right)$; little competitive (26\% $\left.\leq I_{a} \leq 50 \%\right)$; partially competitive $\left(51 \% \leq I_{a} \leq 75 \%\right)$; and fully competitive $\left(76 \% \leq I_{a} \leq 100 \%\right)$.

$$
I_{a}=\sum_{s c=1}^{7} v_{s c_{a}} \times w_{s c}
$$

To calculate the CSF and sub-criteria local importance, pairwise comparisons between criteria located in the same level of the hierarchical structure are developed using the Saaty Fundamental Scale [38]. 


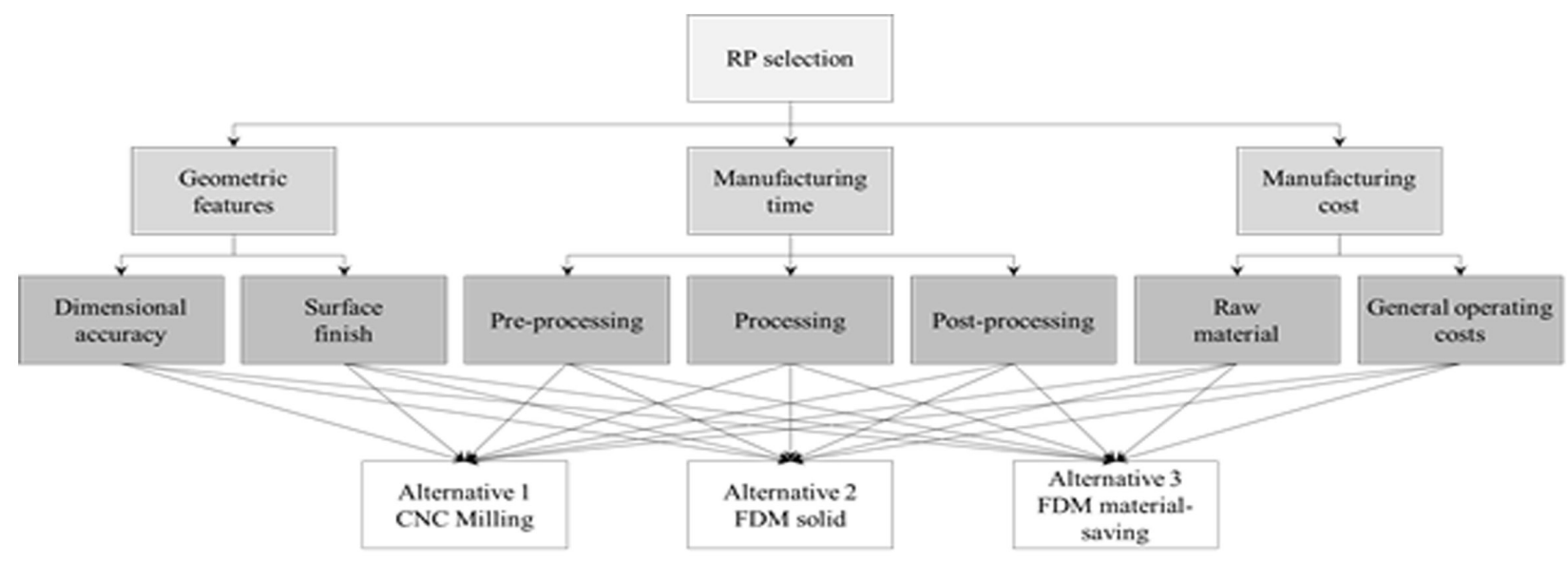

Figure 3. AHP hierarchical structure adopted for RP technique selection.

The pairwise comparison results are described by parity judgment matrices, where each row and column value represents the comparison quantification. Two judgment matrices are necessary: One for the comparison among the three CSF and another for the seven sub-criteria.

The local importance of a CSF or a sub-criteria is given by the ratio between pairwise comparisons value found for the specific CSF or a sub-criteria and the values obtained for all pairwise comparisons described in a parity judgment matrix. As the sub-criteria were developed as a subdivision of the CSF $(f c s)$, the sub-criteria global importance $\left(w_{s c}\right)$ is given by the relativization of the sub-criteria local importance $\left(w l_{s c}\right)$ based on the CSF local importance $\left(w_{f c s}\right)$, according to Eq. (2).

$$
w_{s c}=w l_{s c} x w_{f c s} ; \forall s c \subset f c s
$$

The second part of the performance index identifying the characteristic attributes of the alternatives for each sub-criteria established in the hierarchical structure. As a quantitative study, the attributes were described in different types of numerical scales. To obtain the alternatives ranking on a standard scale, the sub-criteria attributes of the original scales $\left(v^{\prime}{ }_{s c_{a}}\right)$ were standardized $\left(v_{s c_{a}}\right)$ following the pattern verified in the performance index (values between 0\% and $100 \%$ ). Table 2 shows the original scale's conversion to the standardized scale.

The original scale attributes were determined using academic literature for sub-criteria dimensional accuracy and surface finish [1, 9, 31, 32, 33, 34]. The sub-criteria general operating costs, raw material costs, pre-processing, processing, and post-processing times attributes were determined in an estimated manner, given the measurement nature.
The attributes collected in the original scale are converted using the minimum and maximum limits defined for the standardized scale. Based on the limit's standardization for the original and standardized scales, value functions (Table 3) were developed, where intermediate values between the limits are standardized $\left(v_{s c_{a}}\right)$ proportionally to the original value $\left(v^{\prime} s_{a}\right)$. All value functions were originated from the trend curves developed with the maximum and minimum limits of the original and normalized scales. An approximation level close to a statistical generalization coefficient $\mathrm{R}^{2}$ was reached for all subcriteria.

The alternatives ranking step is concluded with technical reports elaboration to describe the performance of each RP process alternative, concerning the established CSF and sub-criteria. This is accomplished in order of summarizing the main points found during the measurement, recommending possible actions to improve the RP techniques performance [39].

\section{Results}

\subsection{CSF and sub-criteria importance}

To quantify the CSF and sub-criteria importance level, 65 ARP and SRP specialists' researchers from Brazilian universities and research institutes were consulted. As result, the CSF Quality was indicated as the most important (40\%), followed by the CSF Cost (34\%), and the CSF Time being indicated as the least important (26\%). Regarding the sub-criteria importance level, the 'dimensional accuracy' and 'general operating costs' sub-criteria present together almost $50 \%$ of relevance among the seven specified 
Table 2. Conversion of the original scales of the sub-criteria to the standardized scale.

\begin{tabular}{|c|c|c|c|c|}
\hline \multirow{2}{*}{ Sub-criteria } & \multicolumn{2}{|c|}{ Original scale $\left(v^{\prime}{ }_{s c_{a}}\right)$} & \multicolumn{2}{|c|}{ Standardized scale $\left(v_{s c_{a}}\right)$} \\
\hline & Minimum & Maximum & Minimum & Maximum \\
\hline \multirow{4}{*}{$\begin{array}{c}\text { Dimensional } \\
\text { accuracy } \\
(\mathrm{mm})\end{array}$} & 0.001 & 0.05 & $76 \%$ & $100 \%$ \\
\hline & 0.05 & 0.1 & $51 \%$ & $75 \%$ \\
\hline & 0.1 & 0.15 & $26 \%$ & $50 \%$ \\
\hline & 0.15 & $>$ & $0 \%$ & $25 \%$ \\
\hline \multirow{4}{*}{$\begin{array}{l}\text { Surface } \\
\text { finish } \\
(\mu \mathrm{m})\end{array}$} & 0.025 & 0.19 & $76 \%$ & $100 \%$ \\
\hline & 0.2 & 1.59 & $51 \%$ & $75 \%$ \\
\hline & 1.6 & 12.49 & $26 \%$ & $50 \%$ \\
\hline & 12.5 & $>$ & $0 \%$ & $25 \%$ \\
\hline \multirow{4}{*}{$\begin{array}{l}\text { Pre-processing } \\
\text { (h) }\end{array}$} & 0 & 0.5 & $76 \%$ & $100 \%$ \\
\hline & 0.5 & 1 & $51 \%$ & $75 \%$ \\
\hline & 1 & 1.5 & $26 \%$ & $50 \%$ \\
\hline & 1.5 & $>$ & $0 \%$ & $25 \%$ \\
\hline \multirow{4}{*}{$\begin{array}{l}\text { Processing } \\
\text { (h) }\end{array}$} & 0.5 & 1 & $76 \%$ & $100 \%$ \\
\hline & 1 & 2 & $51 \%$ & $75 \%$ \\
\hline & 2 & 3 & $26 \%$ & $50 \%$ \\
\hline & 3 & $>$ & $0 \%$ & $25 \%$ \\
\hline \multirow{4}{*}{$\begin{array}{l}\text { Post-processing } \\
\text { (h) }\end{array}$} & 0 & 0.5 & $76 \%$ & $100 \%$ \\
\hline & 0.5 & 1 & $51 \%$ & $75 \%$ \\
\hline & 1 & 1.5 & $26 \%$ & $50 \%$ \\
\hline & 1.5 & $>$ & $0 \%$ & $25 \%$ \\
\hline \multirow{4}{*}{$\begin{array}{l}\text { Raw material } \\
\text { (US\$/year) }\end{array}$} & $<$ & 3636.36 & $76 \%$ & $100 \%$ \\
\hline & 3636.36 & 9090.90 & $51 \%$ & $75 \%$ \\
\hline & 9090.90 & 14545.45 & $26 \%$ & $50 \%$ \\
\hline & 14545.45 & $>$ & $0 \%$ & $25 \%$ \\
\hline \multirow{4}{*}{$\begin{array}{l}\text { General } \\
\text { operating costs } \\
\text { (US\$/year) }\end{array}$} & 36363.64 & 45454.55 & $76 \%$ & $100 \%$ \\
\hline & 45454.55 & 54545.45 & $51 \%$ & $75 \%$ \\
\hline & 54545.45 & 63636.36 & $26 \%$ & $50 \%$ \\
\hline & 63636.36 & $>$ & $0 \%$ & \\
\hline
\end{tabular}

Table 3. Sub-criteria value functions.

\begin{tabular}{cc}
\hline Sub-criteria & Value functions \\
\hline Dimensional accuracy & $v_{1_{a}}=-5.0301\left(v_{1_{a}}^{\prime}\right)+1.0035$ \\
Surface finish & $v_{2_{a}}=-0.121 \ln \left(v_{2_{a}}^{\prime}\right)+0.5556$ \\
Pre-processing & $v_{3_{a}}=-0.5\left(v_{3_{a}}^{\prime}\right)+1$ \\
Processing & $v_{4_{a}}=-0.25\left(v_{4_{a}}^{\prime}\right)+1$ \\
Post-processing & $v_{5_{a}}=-0.5\left(v_{5_{a}}^{\prime}\right)+1$ \\
Raw material & $v_{6_{a}}=-0.0000006\left(v_{6_{a}}^{\prime}\right)+0.9694$ \\
General operating costs & $v_{7_{a}}=-0.00006\left(v_{7_{a}}\right)+2$ \\
\hline
\end{tabular}

sub-criteria. Thus, the importance level interferes with the performance alternatives evaluation, where the alternative can achieve a higher performance in a sub-criteria. The performance is reduced if the subcriteria importance is not representative (i.e., preprocessing time). All consistency indexes in the parity judgments matrix are below the accepted tolerance range of $10 \%$.

\subsection{Alternatives ranking}

Based on the sub-criteria importance and each alternative A1, A2, and A3 attribute, the performance indexes were calculated using the AHP method. Following, the collected attributes are shown according to the CSF.

\subsubsection{CSF quality attribute}

The dimensional accuracy was verified from five readings using four selected prototype positions. These measurements aim to quantify possible dimension deviation errors in prototypes A1, A2, and A3. Table 4 shows the indication of the analyzed dimension position, the result of each measurement, and the average deviation error found. 
The deviation was compared with the prototype projected dimensions. From these comparisons, A3 has a lower average dimensional error in the five evaluated positions, with an average clearance of less than $5 \%$, whereas $\mathrm{A} 1$ and $\mathrm{A} 2$ presenting average clearance errors of $14.2 \%$ and $15 \%$, respectively. The better performance of $\mathrm{A} 3$ is related to the major precision in the tool positioning (the $\mathrm{CNC}$ machining center uses linear spindles, while the $3 \mathrm{D}$ printer uses ball screws spindles).

The roughness was evaluated using the following parameters: The arithmetic mean deviation (Ra); the quadratic mean deviation (Rz); and the total height of the roughness profile (Rt), measured in the opposite direction of the machining and deposition lines to consider the highest roughness values possible. The alternative A3 showed better performance, present- ing lower $\mathrm{Ra}, \mathrm{Rq}$, and Rt averages values than conditions A1 and A2. Additionally, A3 reached an N5 roughness finishing degree ( $\mathrm{Ra}$ between 0.4 to 0.79 $\mu \mathrm{m})$, while $\mathrm{A} 1$ and $\mathrm{A} 2$ reached an $\mathrm{N} 5$ roughness finishing degree (Ra between 6.3 to $12.5 \mu \mathrm{m}$ ), given by the stiffness of the CNC machining center when compared to the $3 \mathrm{D}$ printer.

\subsubsection{CSF time attribute}

The 'total processing time' corresponds to the time interval, in hours, of prototype processing, pre-processing, and post-processing times. For the FDM technique (A1 and A2), the pre-processing time count started with the prototype geometry CAD modeling. The model geometry influences the part (prototype) positioning in the 3D printer's printing board, besides defining the filling and deposition

Table 4. Evaluation of the prototypes' dimensional accuracy.

\begin{tabular}{|c|c|c|c|c|}
\hline Measure & $\mathrm{A} 1$ & $\mathrm{~A} 2$ & A3 & Analyzed dimension position \\
\hline 1 & 29.08 & 29.05 & 29.01 & \\
\hline 2 & 29.06 & 29.06 & 29.01 & \\
\hline 3 & 29.08 & 29.06 & 29.03 & \\
\hline 4 & 29.08 & 29.05 & 29.01 & \\
\hline 5 & 29.07 & 29.05 & 29.06 & \\
\hline Average & 29.07 & 29.05 & 29.02 & \\
\hline Clearance & 0.074 & 0.054 & 0.024 & \\
\hline Measure & $\mathrm{A} 1$ & $\mathrm{~A} 2$ & A3 & Analyzed dimension position \\
\hline 1 & 43.95 & 44.22 & 43.99 & \\
\hline 2 & 43.99 & 44.24 & 44.01 & \\
\hline 3 & 44.03 & 44.25 & 44.03 & \\
\hline 4 & 44.03 & 44.23 & 44.01 & \\
\hline 5 & 44.99 & 44.21 & 43.99 & \\
\hline Average & 44.19 & 44.23 & 44.00 & \\
\hline Clearance & 0.19 & 0.23 & 0.006 & \\
\hline Measure & $\mathrm{A} 1$ & A2 & A3 & Analyzed dime \\
\hline 1 & 9.94 & 9.86 & 10.16 & \\
\hline 2 & 9.97 & 9.94 & 10.12 & \\
\hline 3 & 9.86 & 9.89 & 10.14 & \\
\hline 4 & 9.95 & 9.90 & 10.18 & \\
\hline 5 & 9.96 & 9.88 & 10.02 & \\
\hline Average & 9.93 & 9.89 & 10.12 & \\
\hline Clearance & -0.06 & -0.10 & 0.12 & \\
\hline Measure & A1 & $\mathrm{A} 2$ & A3 & Analyzed dimension position \\
\hline 1 & 8.22 & 8.20 & 8.01 & D \\
\hline 2 & 8.23 & 8.22 & 8.04 & \\
\hline 3 & 8.22 & 8.20 & 8.04 & \\
\hline 4 & 8.24 & 8.21 & 8.03 & \\
\hline 5 & 8.24 & 8.22 & 8.03 & \\
\hline Average & 8.23 & 8.21 & 8.03 & \\
\hline Clearance & -0.23 & -0.21 & -0.03 & \\
\hline
\end{tabular}


material printing positions. On the other hand, the processing time considers the equipment's automatic calibration time, the filling and deposition raw material heating time, and the prototype printing (from the base to the top) time. Finally, the post-processing time corresponds to the required time to filling material remove from the printed prototype through the WaveWash cleaning system.

The 'total processing time' (processing, pre-processing, and post-processing times) required for prototype construction by the FDM process employing the solid (A1) and material-saving (A2) functions are shown in Table 5. Except for the prototype printing time, all other operations require the same time to be performed. The greater time to manufacture A1 is given by the material volume deposited compared to A2.

For CNC milling (A3), the pre-processing time considered prototype geometry CAD modeling and CAM programming. The 'total processing time' constitutes the summation of the time required for raw material cutting and positioning on the $\mathrm{CNC}$ machining center, the machine's coordinate system calibration, and machining execution. Post-processing operations on the machined prototype are not necessary for CNC milling. The 'total processing time' and times required to processing, pre-processing, and post-processing for prototype construction by $\mathrm{CNC}$ milling (A3), compiled in Table 6.

The ARP technique pre-processing time is shorter than SRP, and the processing and post-processing times are longer. Ultimately, the 'total processing time' using the SRP technique is about 52\% less than the solid ARP function and $36 \%$ less than the material-saving ARP function.

Table 5. Processing, pre-processing, and post-processing times required for prototype construction by FDM process employing the solid (A1) and material-saving (A2) functions.

\begin{tabular}{|c|c|c|c|}
\hline & \multirow{2}{*}{ Description } & \multicolumn{2}{|c|}{ Time (h) } \\
\hline & & A1 & A2 \\
\hline & CAD modeling & 00:08:27 & 00:08:27 \\
\hline \multirow[t]{3}{*}{ Pre-processing } & Open STL file and prototype positioning in the board & 00:08:05 & 00:08:05 \\
\hline & Load material & 00:05:09 & 00:05:09 \\
\hline & Heating & 00:12:11 & $00: 12: 11$ \\
\hline \multirow[t]{2}{*}{ Processing } & Calibration & 00:02:08 & 00:02:08 \\
\hline & Prototype printing (deposited and filling material printing) & 03:11:00 & 02:28:00 \\
\hline \multirow[t]{4}{*}{ Post-processing } & Filling material removal & 00:00:23 & 00:00:23 \\
\hline & Pre-processing time & $00: 21: 41$ & $00: 21: 41$ \\
\hline & Processing time & 03:25:19 & $02: 42: 19$ \\
\hline & Post-processing time & $00: 00: 23$ & $00: 00: 23$ \\
\hline
\end{tabular}

Table 6. Processing, pre-processing, and post-processing times required for prototype construction by CNC milling process (A3).

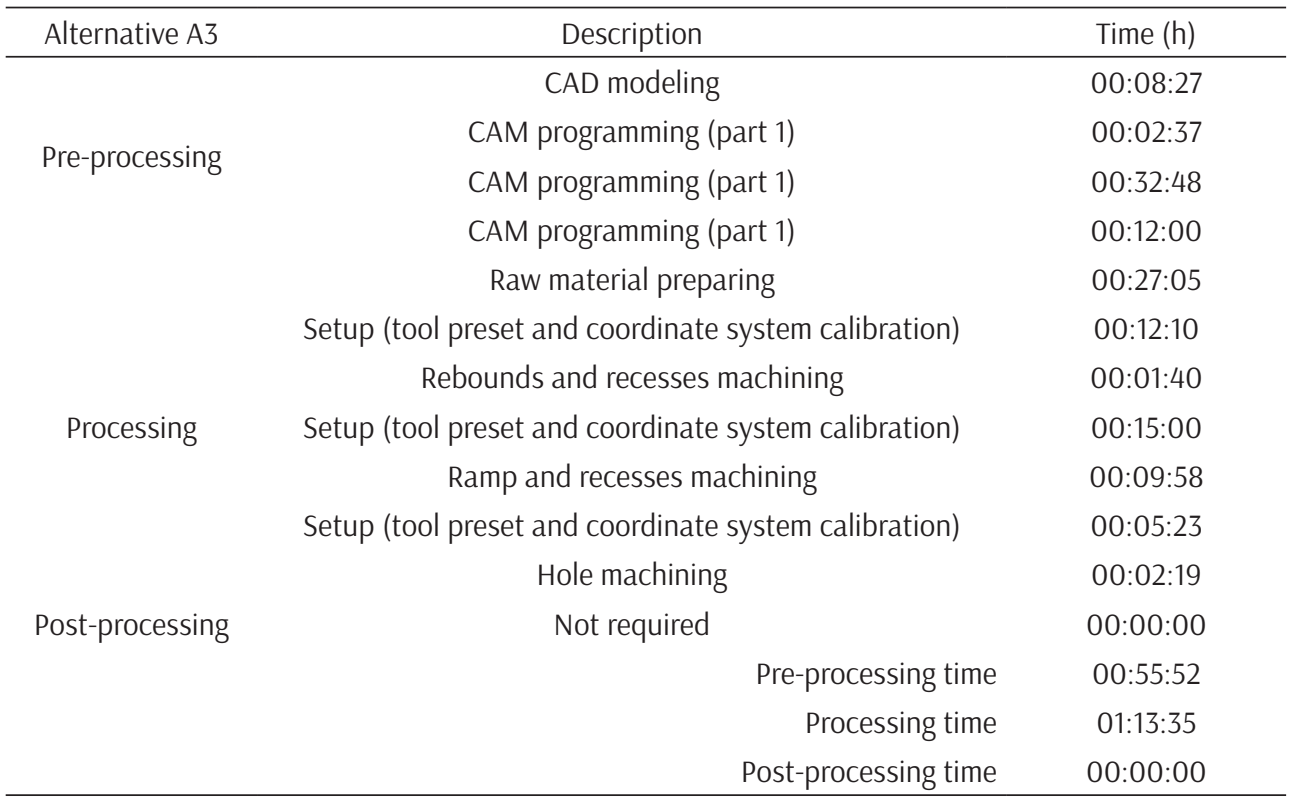




\subsubsection{CSF cost attribute}

The cost calculation considers the prototype 'total processing time' and general operating and the raw material costs, considering an annual manufacture time of 1920 hours, working 8 hours per day, 20 days per month for 12 months. The manufacture volume value is given by the prototype 'total processing time' calculated, and the number of hours available per year. Thus, 561 (A1), 709 (A2), and 1565 (A3) units were projected to be manufactured.

For the FDM technique, both deposited and filling raw material are commercially supplied in 688 $\mathrm{cm}^{3}$ cartridges for US $\$ 327.27$. For A1, the deposited raw material mass was $67 \times 10^{-3} \mathrm{~kg}$, with a volume of $72.91 \times 10^{-6} \mathrm{~m}^{3}$ and density of $918.94 \mathrm{~kg} / \mathrm{m}^{3}$, totaling a deposited raw material cost of US $\$ 517.83 / \mathrm{kg}$. Following the same logic, the filling raw material mass was $4 \times 10^{-3} \mathrm{~kg}$ and a volume of $3.6 \times 10^{-6} \mathrm{~m}^{3}$, costing US $\$ 435.25 / \mathrm{kg}$. Thus, the material cost of A1 was US $\$ 36.36$. For A2, the deposited raw material mass was $34 \times 10^{-3} \mathrm{~kg}$, with a volume of $3.54 \times 10^{-6} \mathrm{~m}^{3}$ and density of $964.81 \mathrm{~kg} / \mathrm{m}^{3}$, totaling a deposited raw material cost of US $\$ 493.03 / \mathrm{kg}$. The filling raw material mass was $4 \times 10^{-3} \mathrm{~kg}$ and a volume of $3.6 \times 10^{-6} \mathrm{~m}^{3}$, costing US $\$ 436.44 / \mathrm{kg}$. Thus, the material cost of the A2 prototype was US $\$ 18.51$. For A3, the raw material costs US $\$ 12.09 / \mathrm{kg}$. The workpiece for prototype machining measures $60 \times 64 \mathrm{~mm}^{2}$, enabling the cutting of 15 workpieces per raw material bar. Thus, the workpiece is $184 \times 10^{-3} \mathrm{~kg}$ and the machined prototype is $73 \times 10^{-3} \mathrm{~kg}$, the unit cost is US\$ 2.23 for the workpiece and US $\$ 0.88$ for the prototype. The difference between the workpiece and prototype mass is $73 \times 10^{-3} \mathrm{~kg}$, indicating a mass value of $112 \times 10^{-3} \mathrm{~kg}$ of residue (chip) for US $\$ 1.43 / \mathrm{kg}$. Thus, the material cost of the A3 prototype was US $\$ 2.33$.

The FDM printer cost is US $\$ 25272.73$, and the auxiliary WaveWash cleaning system costs US $\$$ 545.45. The computer required to operate the FDM equipment has a cost of US\$ 636.36 and CAD software of US $\$ 4002.99$. The maintenance cost of the FDM printer is US\$ 3090.90 per year, covering all spare parts in the period. The depreciation cost of the FDM printer is US $\$ 3227.27$ per year, US\$ 127.27 for the computer, and US $\$ 800.60$ for the CAD software.

Regarding consumables, the FDM printer features two consumables required for the printing process. The first is the printing board, sold in boxes of 24 pieces for US $\$ 200.00$. The second consumable is a detergent used in the WaveWash cleaning system to remove the filling material, which costs US $\$ 200.00$ for a box with 24 pieces. Computer consumables are paper, print cartridges, and office supplies, estimated at a value of US\$ 327.27. The CNC machining center with CAM software costs US\$ 81818.18, also considering the fixing vise US $\$ 472.72$, a set of clamps of US $\$ 212.72$, and a set of shims at a value of US\$ 178.18. The CNC machining center maintenance cost corresponding to US $\$ 8268.18$ per year for an annual depreciation of US $\$ 16536.36$. As the FDM printer, the $\mathrm{CNC}$ machining center requires the purchase of computer and CAD software, with acquisition and depreciation values equivalent to those described for the FDM. The depreciation of the CAM software is US $\$ 1665.05$. The cost of consumables is estimated at US\$ 909.09.

To calculate the rental cost, an area of $200 \mathrm{~m}^{2}$ was estimated at an average cost of US $\$ 6.85 / \mathrm{m}^{2}$, and the machine operator cost was calculated based on the average salary of a Brazilian CNC programmer, equivalent to US $\$ 581.81$. Finally, the estimated electricity consumption was given by the annual energy consumption of the equipment and the value of the light tariff. The FDM equipment consumed 1.32 $\mathrm{kWh}$, and the CNC machining center $25.70 \mathrm{kWh}$. The B3 consumer tariff is equivalent to US $\$$ 0.092/ kWh.

\subsection{Alternatives' performance index}

To verify the performance of the alternatives using a multi-criteria decision method, two information sources were necessary: The CSF and sub-criteria importance and the data collection regarding the alternatives' performance in each sub-criteria. The AHP multi-criteria decision method was applied and A1, A2, and A3 performance were ranked. The ranking results show a little competitive performance for A1 $\left(\mathrm{I}_{1}=47 \%\right)$, partially competitive performance for A2 $\left(\mathrm{I}_{2}=52 \%\right)$, and partially competitive performance for A3 $\left(\mathrm{I}_{3}=68 \%\right)$, where no alternatives achieved fully competitive performance $\left(76 \% \leq I_{a} \leq 100 \%\right)$. The alternative A3 presented good performance mainly in the dimensional accuracy and surface finish sub-criteria. The dimensional accuracy data of A3 showed errors measured on the order of hundredths of millimeters, while $\mathrm{A} 1$ and $\mathrm{A} 2$ showed errors on the order of tenths of millimeters. The alternative A3 also exhibited better performance on the sub-criteria related to the raw material cost and processing time.

Specifically, for the CSF Quality, since the extruder nozzle has a fixed thickness which difficult the manufacture thin regions using an FDM technique. Also, the stair-stepping effect typical of ARP process- 
es negatively influences on accuracy and finishing of A1 and A2. On the other hand, for the CNC milling case, the accuracy and finishing are limited only by tools geometry and to eventual wear and damage. These limitations did not influence the accuracy and finish of A3.

For the CSF Cost, A3 produces waste (chips). For each workpiece, approximately $0.111 \mathrm{~kg}$ of raw material was transformed into chips and thus discarded. Approximately 1.5 prototypes could be manufacture with raw-material waste. Compared to the ABS cartridges cost of employed on $\mathrm{A} 1$ and $\mathrm{A} 2$, the material disposal cost in A3 is not substantial, even with the material savings shown for A1 and A2, in which the waste is below $5 \%$ of the feedstock. The alternative A1 produced a prototype with greater raw materials consumption of ARP techniques, reaching the worst result, being classified as non-competitive. The alternative $\mathrm{A} 2$, in which the material saving function was adopted, the material saving was not enough to obtain a classification higher than the little competitive one.

In general, processing costs, maintenance of the FDM printer with spare parts is $60 \%$ less than the $\mathrm{CNC}$ machining center. Although the $\mathrm{CNC}$ machine is very resistant and presents few problems under normal working conditions, as well as minor typing errors, can cause collisions, which represent the high-cost manutention. Regarding the hardware and software depreciation cost, the FDM does not need CAM software, as well as the exchange of cutting tools, oil, grease, cutting fluid, and other inputs needed in CNC machining. The alternative A3 has the highest cost in depreciation and inputs. For operator cost, although ARP techniques require a less trained operator, the dependency on CAD modeling requires an operator with qualified knowledge. One option would be for the CNC machining center operator to work on both types of equipment, as the FDM printing requires little human intervention. Regarding the rental cost, the value is the same for both machines, as they can work side by side. Thus, the performance of general processing costs shows that $\mathrm{A} 1$ and A2 are fully competitive, whereas A3 is not competitive, mainly due to the high costs of depreciation, inputs, and maintenance of the $\mathrm{CNC}$ machine compared to the FDM.

For the CSF Time, the whole CNC machine operation is faster compared with the FDM process. In general, A1 obtained a non-competitive performance for the processing time, requiring $3.42 \mathrm{~h}$ to execute the entire prototyping operation. The alternative A2 is a little competitive on processing, requiring less deposition of raw material, and was executed during
$2.70 \mathrm{~h}$. Finally, the best performance was verified for A3, requiring $1.22 \mathrm{~h}$ for prototyping, approximately three times less time compared to A1.

\section{Conclusion}

A comparative analysis among additive and subtractive rapid prototyping techniques was developed to determine which approach presents technical and economic viability for physical prototype manufacturing. The main conclusions can be listed as follows:

- AHP method can be used to select rapid prototyping processes, considering technical and economic factors. Previous tests with other similar decision-making methods (the Fuzzy AHP) showed similar results;

- Both evaluated rapid prototyping techniques no reached the maximum performance under the analyzed evaluation criteria;

- The additive rapid prototyping technique presented less dimensional accuracy and worse finish than the subtractive rapid prototyping;

- The manufacturing cost by additive rapid prototyping technique is higher compared with the subtractive rapid prototyping technique due to the higher general operating and the raw-material costs;

- The additive rapid prototyping technique demanded a longer manufacture time than the subtractive alternative, mainly due to the low deposition rate;

- The subtractive rapid prototyping technique is the most suitable alternative for manufacturing prototypes, according to the analyzed evaluation criteria;

- The results achieved using the additive and subtractive rapid prototyping techniques adopted within this study must not be generalized. The calculated performance index is valid for prototypes with similar characteristics as dimensions shape and raw material;

- The results obtained can be compared with the results' behavior found in other studies addressed to the AHP usage in specific for additive rapid prototyping technique selection. As a summary, in [23] the FDM was considered an appropriate technology for rapid 
prototyping, where in [24] a comparison with 45 machines indicates goods results for the CJP usage. In [25] the ranking sequence is the LIFT after the microstereolithography, micro-SLS, and micro-3D printing. The results verified in [32] and [34] show the highest priority for the selective laser Sintering process compared with the fused deposition modeling, stereolithography, and 3D printing process. In general, the articles presented in Table 1 are focused on showing the selection efficiency of the method developed, not focusing on indicating the ideal rapid prototyping technique based on the criteria used for analysis; and

- In future research, the prototype's geometry evaluation in a coordinate measuring machine could be developed to compare the dimensional quality of the physical prototype with the prototype project to verify errors presented by the alternatives. Also, an approach considering the use of alternatives related to hybrid manufacturing, sharing additive and subtractive manufacturing in the same process, can contribute to improving the rapid prototype efficiency.

\section{Funding}

This work was partially supported by the Brazilian National Council for Scientific and Technological Development (CNPq) [grant number 422095/2018-4].

\section{References}

[1] M. Bordoni and A. Boschetto, "Thickening of surfaces for direct additive manufacturing fabrication," Rapid Prototyping J., vol. 18, no. 4, pp. 308-318, Jun. 2012, doi:10.1108/13552541211231734.

[2] S. Bai and F. Hu, "The Role of Rapid Manufacturing Technology in Industrial Design," IOP Conf. Ser.: Mater. Sci. and Eng., vol. 382, no. 3, pp. 2-7, 2018, doi:10.1088/1757-899X/382/3/032011.

[3] S. Modal, A. K. Singh, P. Chatterjee, and S. Chakraborty, "Decision Making for Rapid Prototyping Process Selection Using Complex Proportional Assessment Method," in Int. Conf. Manuf. Excellence, Nashik, India, 2017, pp. 1 - 7.

[4] B. Camburn, V. Viswanathan, J. Linsey, D. Anderson, D. Jensen, R. Crawford, K. Otto, and K. Wood, "Design prototyping methods: state of the art in strategies, techniques, and guidelines," Des. Sci., vol. 3, no. e13, pp. 1-33, Aug. 2017, doi:10.1017/dsj.2017.10.

[5] C. W. Elverum, T. Welo, and S. Tronvoll, "Prototyping in New Product Development: Strategy Considerations," Procedia CIRP, vol. 50, no. 1, pp. 117-122, 2016, doi:10.1016/j.procir.2016.05.010.
[6] D. T. Díaz, "Tecnologías de Fabricación Digital Aditiva, ventajas para la construcción de modelos, protótipos y series cortas em el processo de diseño de produtos," Iconofacto, vol. 12, no. 18, pp. 118-143, 2016, doi:10.18566/v12n18. a07.

[7] S. I. A. Kudus, R. I. Campbell, and R. Bibb, "Customer perceived value for self-designed personalised products made using additive manufacturing," Int. J. Ind. Eng. Manag., vol. 7, no. 4, pp. 183-193, Dec. 2016.

[8] M. Carfagni, L. Fiorineschi, R. Furferi, L. Governi, and F. Rotini, "The role of additive technologies in the prototyping issues of design," Rapid Prototyping J., vol. 24, no. 7, pp. 1101-1116, Oct. 2018, doi:10.1108/RPJ-02-2017-0021.

[9] H. Byun and K. Lee, "A decision support system for the selection of a rapid prototyping process using the modified TOPSIS method," The Int. J. Adv. Manuf. Tech., vol. 26, no. 11-12, pp. 1338-1347, Nov. 2005, doi:10.1007/s00170004-2099-2.

[10] Y. Qin, Q. Qi, P. J. Scott, and X. Jiang, "An additive manufacturing process selection approach based on fuzzy Archimedean weighted power Bonferroni aggregation operators," Robot. and Computer-Integrated Manuf., vol. 64, Aug. 2020, Art. no. 101926, doi:10.1016/j. rcim.2019.101926.

[11] R. I. Campbell and M. R. N. Bernie, "Creating a database of rapid prototyping system capabilities," J. Mater. Process. Tech., vol. 61, no. 1-2, pp. 163-167, Aug. 1996, doi:10.1016/0924-0136(96)02481-8.

[12] M. M. Ghazy, "Development of an additive manufacturing decision support system (AMDSS)," Ph.D. dissertation, Dept. Sci. Agri. Eng., Newcastle Univ., Newcastle, England, 2012.

[13] D. T. Pham and R. S. Gault, "A comparison of rapid prototyping technologies,” Int. J. Mach. Tools and Manuf., vol. 38, no. 10-11, pp. 1257-1287, Oct. 1998, doi:10.1016/ S0890-6955(97)00137-5.

[14] R. Bibb, Z. Taha, R. Brown, and D. Wright, "Development of a rapid prototyping design advice system," J. Intell. Manuf., vol. 10, no. 3, pp. 331-339, Sept. 1999, doi:10.1023/A:1008920512663.

[15] H. Lan, H. Ding, and J. Hong, "Decision support system for rapid prototyping process selection through integration of fuzzy synthetic evaluation and an expert system," Int. J. Prod. Res., vol. 43, no. 1, pp. 169-194, 2005. doi:10.1080/0 0207540410001733922.

[16] S. H. Masood and A. Soo, "A rule based expert system for rapid prototyping system selection," Robot. and ComputerIntegrated Manuf., vol. 18, no, 3-4, pp. 267-274, Jun./Aug. 2002, doi:10.1016/S0736-5845(02)00017-0.

[17] J. Munguía, J. Lloveras, S. Llorens, and T. Laoui, "Development of an AI-based rapid manufacturing advice system,” Int. J. Prod. Res., vol. 48, no. 8, pp. 2261-2278, 2010. doi:10.1080/00207540802552675.

[18] A. Bernard, A. Deglin, and G. Ris, "An original approach for the memorisation and the generation of rapid product development processes," Rapid Prototyping J., vol. 9, no. 2, pp. 58-67, May. 2003, doi:10.1108/13552540310467068.

[19] B. Singh and N. Sewell, "Knowledge based process planning and design for additive manufacturing (KAR-MA)," in Proc. 5th Int. Conf. Adv. Res. and Rapid Prototyping, Exeter, England, 2011.

[20] M. Braglia and A. Petroni, "A management-support technique for the selection of rapid prototyping technologies,” J. Ind. Tech., vol. 15, no. 4, pp. 2-6, 1999.

[21] A. Armilotta, "Selection of layered manufacturing techniques by an adaptive AHP decision model," Robot. Computer-Integrated Manuf., vol. 24, no. 3, pp. 450-461, Jun. 2008, doi:10.1016/j.rcim.2007.06.001 . 
[22] A. Borille, J. Gomes, R. Meyer, and K. Grote, "Applying decision methods to select rapid prototyping technologies," Rapid Prototyping J., vol. 16, no. 1, pp. 50-62, Jan. 2010, doi:10.1108/13552541011011712.

[23] K. Lokesh and P. K. Jain, "Selection of rapid prototyping technology,” Adv. Prod. Eng. Manage., vol. 5, no. 2, pp. 7584, Jun. 2010. [Online]. Avaiable: https://apem-journal.org/ Archives/2010/VOL05-ISSUE02.html

[24] C. G. Mançanares, E. S. Zancul, J. C. Silva, and P. A. C. Miguel, "Additive manufacturing process selection based on parts' selection criteria," Int. J. Adv. Manuf. Tech., vol. 80, no. 5-8, pp. 1007-1014, Sept. 2015, doi:10.1007/ s00170-015-7092-4.

[25] M. B. Anand and S. Vinodh, "Application of fuzzy AHPTOPSIS for ranking additive manufacturing processes for microfabrication," Rapid Prototyping J., vol. 24, no. 2, pp. 424-435, Mar. 2018, doi:10.1108/RPJ-10-2016-0160.

[26] U. K. Zaman, M. Rivette, A. Siadat, and S. M. Mousavi, "Integrated product-process design: Material and manufacturing process selection for additive manufacturing using multi-criteria decision making," Robot. and Computer-Integrated Manuf., vol. 51, no. 1, pp. 169-180, Jun. 2018, doi:10.1016/j.rcim.2017.12.005.

[27] Y. Wang, R. Y. Zhong, and X. Xu, "A decision support system for additive manufacturing process selection using a hybrid multiple criteria decision-making method," Rapid Prototyping J., vol. 24, no. 9, pp. 1544-1553, Nov. 2018, doi:10.1108/RPJ-01-2018-0002.

[28] S. Kadkhoda-Ahmadi, A. Hassan, and E. Asadollahi-Yazdi, "Process and resource selection methodology in design for additive manufacturing," The Int. J. Adv. Manuf. Tech., vol. 104, no. 5-8, pp. 2013-2029, Oct. 2019, doi:10.1007/ s00170-019-03991-w.

[29] I. Peko, N. Gjeldum, and B. Bilić, "Application of AHP, Fuzzy AHP and PROMETHEE Method in Solving Additive Manufacturing Process Selection Problem," Tehnički vjesnik, vol. 25, no. 2, pp. 453-461, 2018, doi:10.17559/TV-20170124092906.

[30] A. Borille and J. O. Gomes, "Selection of additive manufacturing technologies using decision methods," in Rapid Prototyping Tech. - Princ. and Functional Requirements, E. Hoque, Ed., London, England: IntechOpen, 2011, pp. 29-54.

[31] R. E. Breaz, O. R. Bologa, and G. Sever, "Selecting between CNC milling, robot milling and DMLS processes using a combined AHP and fuzzy approach," Procedia Comput. Sci., vol. 122, no. 1, pp. 796-803, 2017, doi:10.1016/j. procs.2017.11.439.

[32] I. Peko, D. Bajić, and I. Veža, "Selection of additive manufacturing process using the AHP method," in Proc. Mech. Technol. and Structural Mater., Split, Croatia, 2015, pp. 1-11.

[33] V. Kumar, L. Kumar, and A. Haleem, "Selection of rapid Prototyping technology using an ANP based approach," IOSR J. Mech. and Civil Eng., vol. 13, no. 4, pp. 71-78, Jul./Aug. 2016, doi:10.9790/1684-13040647178.

[34] B. N. Panda, B. B. Biswal, and B. B. L. V. Deepak, "Integrated AHP and fuzzy TOPSIS approach for the selection of a rapid prototyping process under multi-criteria perspective," in Proc. 5th Int. \& 26th All India Manuf. Technol. Des. Res. Conf., Guwahati, India, 2014, pp. 1-6.

[35] S. K. Singhal, A. P. Pandey, P. M. Pandey, and A. K. Nagpal, "Optimum part deposition orientation in stereolithography," Computer-Aided Design and Applications, vol. 2, no. 1-4, pp. 319-328, 2005, doi: 10.1080/16864360.2005.10738380.

[36] B. N. Panda, R. M. Bahubalendruni, B. B. Biswal, and M. Leite, "A CAD-based approach for measuring volumetric error in layered manufacturing," Proceedings of the
Institution of Mechanical Engineers, Part C: Journal of Mechanical Engineering Science, vol. 231, no. 13, pp. 2398-2406, 2017, doi: 10.1177/0954406216634746.

[37] R. Nayak, M. V. A. Bahubalendruni, B. B. Biswal, and P. P. Chauhan, "An approach towards economized 3D printing," In Applied Mechanics and Materials, vol. 852, pp. 185-191, 2016, doi: 10.4028/www.scientific.net/AMM.852.185.

[38] T. L. Saaty, and V. Ramanujam, "An objective approach to faculty promotion and tenure by the analytic hierarchy process,” Res. Higher Educ., vol. 18, no. 3, pp. 311-331, Sept. 1983, doi:10.1007/BF00979603.

[39] A. N. Júnior and L. R. Guimarães, "A greedy randomized adaptive search procedure application to solve the travelling salesman problem,” Int. J. Ind. Eng. Manage., vol. 10, no. 3, pp. 238-242, Sept. 2019, doi:10.24867/IJIEM-2019-3-243.

\section{Appendix A. Acronyms}

3DP: Three-dimensional printing;

ABS: Acrylonitrile butadiene styrene;

AHP: Analytic hierarchy process;

ARP: Additive rapid prototyping techniques;

CAD: Computer-aided design;

CAM: Computer-aided manufacturing;

CJP: Colorjet printing;

CNC: Computer numerical control;

CSF: Critical success factors;

DLP: Digital light processing;

DMLS: Direct metal laser sintering;

FDM: Fused deposition modeling;

IJM: Jet-wax;

IJP: Inkjet printing;

LOM: Laminated object manufacturing;

M3DP: Masked three-dimensional printing;

MAUT: Multi-attribute utility theory;

MCDM: Multi-criteria decision-making-based;

MJP: Multijet printing;

MSLA: Masked stereolithography;

MSLS: Masked selective laser;

PJ: Jet-photopolymer;

PROMETHEE: Preference ranking organization method for enrichment evaluation;

RP: Rapid prototyping;

SLA: Stereolithography apparatus;

SLS: Selective laser;

SGC: Solid ground curing;

SRP: Subtractive rapid prototyping techniques;

TDP: Technical data package;

TOPSIS: Technique for order of preference by similarity to ideal solution. 